\title{
Synergistic Antioxidant Action of Oregano, Ajowan and Borage Extracts
}

\author{
Hafeeza Khanum, Kulathooran Ramalakshmi, Pullabhatla Srinivas, Babasaheb Bhaskarrao Borse \\ Plantation Products Spices and Flavour Technology Department, Central Food Technological Research Institute, Council of Scien- \\ tific and Industrial Research (CSIR), Mysore, India. \\ Email: bbborase@yahoo.com
}

Received February 28 $8^{\text {th }}, 2011$; revised April 11 ${ }^{\text {th }}, 2011$; accepted April $18^{\text {th }}, 2011$.

\begin{abstract}
Radical scavenging activity (RSA), antioxidant activity (AA), reducing power, total polyphenol (TP) and flavonoid contents (TFC) of oregano (Oreganum vulgare spp.), ajowan (Trachyspermum ammi) and Indian borage (Plectranthus amboinicus) extracts were evaluated. Oregano exhibited maximum radical scavenging activity $(88.2 \%, 82.3 \%)$ for aqueous and ethanolic extracts at 50 ppm concentration respectively, followed by ajowan (86.9\%, 68.4\%) and Indian borage $(30.5 \%, 30.4 \%)$. Extracts of oregano and ajowan showed better antioxidant activity and reducing power than that of Indian borage. Aqueous extracts of oregano had highest TP (Gallic acid equivalents) and TFC (Catechin equivalents) of $27.7 \%$ and $50.6 \%$ respectively compared to ajowan $(6.7 \%, 24.4 \%$ ) and Indian borage (4.2\%, 5.5\%). Synergistic studies showed that the addition of oregano extract appreciably enhanced the RSA of ajowan and Indian borage extracts even at 50 ppm concentration.
\end{abstract}

Keywords: Oreganum vulgare, Trachyspermum ammi, Pleactranthus amboinicus, Antioxidant Activity, Synergistic Action

\section{Introduction}

Bioactive compounds from plant and microbial sources are gaining importance in recent years. Some of these constituents with antioxidant activity found in plants are reported to play a critical role in delay of the onset as well as prevention of many chronic degenerative diseases such as oxidative stress, inflammation, DNA oxidation, cancer and ageing [1]. Spices and herbs, in addition to contributing to taste and aroma of foods, also contain a variety of bioactive molecules with ability to quench free radicals [2]. The antioxidant activity of herbs and spices, generally attributed to their phenolic constituents, has been demonstrated in many studies over recent years [3, 4]. Essential oil components are the volatiles responsible for the flavour of spices, which show potent antimicrobial and antioxidant activities. Hence, these do serve as natural food preservatives. Volatile extracts are prepared by hydro-distillation to isolate the intrinsic flavour compounds from the plant material. Aqueous extracts, on the other hand, would disperse more easily in food systems and also the process of extraction obviates organic solvent residues.

Nutritional, anti-oxidant, anti-microbial and other medi- cinal properties of spices and herbs have important implications [5]. In the present scenario, the anti-diabetic, anti-hypercholesterolemic, anti-carcinogenic and antiinflammatory effects of spices have paramount importance as diabetes, cardio-vascular diseases, arthritis and cancer are the present key health issues of mankind. Recent studies have shown that the consumers' demand for health-promoting food products containing the bioactive principles isolated from plant materials is increasing. Importance of replacing synthetic antioxidants by natural ingredients from herbs and spices and other plant materials has increased due to health implications and increased functionality like improved solubility in both, lipophilic and aqueous systems. It is well known that natural antioxidants extracted from herbs and spices (rosemary, sage, thyme etc.) have high antioxidant activity and are used in many food applications [6]. Most of the antioxidant potential of herbs and spices is due to the redox properties of phenolic moieties, which allow them to act as reducing agents, hydrogen donators and singlet oxygen quenchers [7].

Oregano, a perennial herbaceous plant belonging to Labiates family, grows in Mediterranean regions and 
western Asia. Oregano well known as the "pizza herb" is used in fresh as well as dry form to enhance the flavor, especially of tomato based products, baked goods and meat products. Typically, it has a phenolic, herbaceous, slightly floral and bitter taste, with slight lemony and pungent notes. Carvacrol is the major component of oregano oil which is mainly responsible for its anti-microbial activity. Ajowan (Trachyspermum ammi) is one of the aromatic seed spice with medicinal value. The effect of ajowan ethanolic extract (AEE) was evaluated on the mycelia growth and spore germination of few fungi such as A. ochraceus, A. flavus, Fusarium sp., Pencillium sp., A. niger and A. oryzae. Antifungal property was observed against all isolates by well assay [8]. Thymol, the major phenolic compound present in ajowan, has been reported to be a germicide, antispasmodic and anti- fungal agent. Indian Borage (Plectranthus aromaticus) is a small plant with fleshy stem, thick textured lemon scented leaves with bitter and pungent taste. It is reported to contain active ingredient carvacrol (50.7\%) along with volatile constituents like caryophyllene $(13.1 \%)$ and patchoulane $(8.7 \%)$. It is used in pharmacology for indigestion, diarrhea, chronic cough, renal calculi and convulsions. Indian borage oil (IBO) has been found to inhibit the radial growth of mycelia and exhibit broad fungitoxic properties against various fungi tested [9].

While the volatiles of these materials have been well studied both for their constitution and bioactive properties, the non-volatile components were explored to a lesser extent. In this context, oregano (Origanum vaulgare), ajowan (Trachyspermum ammi) and Indian borage (Plectranthus amoboinicus) were chosen for preparation of aqueous and alcoholic extracts and analyzed for their antioxidant potential employing different in vitro model systems. Also, synergistic action of these extracts was investigated.

\section{Materials and Methods}

\subsection{Chemicals and Reagents}

Tween-40, $\beta$-carotene, linoleic acid, 1,1-diphenyl-2picrylhydrazyl (DPPH) were obtained from Sigma-Aldrich Chemical Co., (St. Louis, MO). Folin-Ciocalteau reagent, catechin and butylated hydroxyanisole (BHA) were obtained from Fluka, Switzerland. All other chemicals and solvents used were of analytical grade obtained from Rankem, New Delhi, India.

\subsection{Materials}

Fresh ajowan seeds were procured from an authentic source at local market in Mysore, India. Fresh leaves of P. amboinicus and Origanum vaulgare were collected from local gardens of Mysore, Ooty and India during the month of February. The chairman, Department of Studies in Botany, University of Mysore, India, performed the botanical identification. The fresh leaves were dried to a moisture content $<7 \%$ in a through-flow convective drier connected to a dehumidifier (Bry-Air, Haryana, India, model: CFM-FFB-170) at $50^{\circ} \mathrm{C}$ at relative humidity of $30 \%$, and stored at room temperature.

\subsection{Methods}

\subsubsection{Preparation of Extracts}

All the dried herbs were ground in a mixer (Butterfly, India) and extracted with aqueous ethanol $(50 \%)$ in a column extractor for $8 \mathrm{~h}$. The eluent was desolventized in a rotary evaporator (Heidolph, Germany) at $40^{\circ} \mathrm{C}$ and 40 mbar pressure. The extract obtained was stored at $8^{\circ} \mathrm{C}$.

In another experiment all the herbal powders were extracted with boiling water for $5 \mathrm{~min}$ and the aqueous solution was dried in the freeze drier at $-40^{\circ} \mathrm{C}$ to $-45^{\circ} \mathrm{C}$ and 4 - 5 mbar for $19 \mathrm{~h}$. The dried extracts were stored at $8^{\circ} \mathrm{C}$.

\subsubsection{Evaluation of Antioxidant Potential of Extracts}

The extracts were evaluated for antioxidant potential through in vitro model systems such as $\beta$-carotenelinoleate model system (antioxidant activity-AA), 1,1-diphenyl-2-picrylhydrazyl (DPPH, radical scavenging activity) and Iron reducing capacity (reducing power).

\subsection{3. $\beta$-Carotene and Linoleic Acid Assay}

Antioxidant activity based on coupled oxidation of $\beta$-carotene and linoleic acid was evaluated with some modification of the method described by Taga, Miller \& Pratt [10]. $\beta$-Carotene $(4 \mathrm{mg})$ was dissolved in chloroform $(10 \mathrm{ml})$. An aliquot $(5 \mathrm{ml})$ of the solution was mixed with linoleic acid $(60 \mathrm{mg})$ and Tween-40 $(600 \mathrm{mg})$. Chloroform was removed under reduced pressure (40 mbar) using a rotavapour. Oxygenated distilled water $(120 \mathrm{ml})$ and triple distilled water $(30 \mathrm{ml})$ were added into the $\beta$-carotene emulsion and contents were mixed well. Aliquots $(4 \mathrm{ml})$ of the oxygenated $\beta$-carotene emulsion and $1 \mathrm{ml}$ of extracts at different concentrations were placed in test tubes and incubated at $50^{\circ} \mathrm{C}$ in a water bath. Oxidation of $\beta$-carotene emulsion was monitored by measuring absorbance at $470 \mathrm{~nm}$ (Ultraviolet-Visible Spectrometer, Cintra 10, GBC, Australia). Absorbance was measured at intervals of $30 \mathrm{~min}$ till the solution turned colorless (180 min).

A control was prepared by using $1 \mathrm{ml}$ of ethanol instead of the extracts. The antioxidant activity (AA) of the extracts was calculated in terms of photo-oxidation of $\beta$-carotene using the following expression

$$
\mathrm{AA}=100\left[1-\left(\mathrm{A}_{0}-\mathrm{A}_{T}\right) /\left(\mathrm{A}_{0}^{0}-\mathrm{A}_{t}^{0}\right)\right]
$$


wherein, $A_{0}$ is the initial absorbance of sample, $A_{t}$ the absorbance of sample after time t, $A_{0}^{0}$ is the initial absorbance of control and $\mathrm{A}_{t}^{0}$ is the absorbance of control after time $t$.

\subsubsection{Reducing Power Assay}

The reducing power of the extracts was measured according to the method of Oyaizu [11]. Extracts $(0.5 \mathrm{ml})$ at various concentrations $(0.5,1.0,1.5$ and $2 \mathrm{mg} / \mathrm{ml})$ was mixed with $2.5 \mathrm{ml}$ of phosphate buffer $(0.2 \mathrm{M}, \mathrm{pH} 6.6)$ and $2.5 \mathrm{ml}$ of potassium ferricyanide (1\%). The mixture was incubated at $50^{\circ} \mathrm{C}$ for $20 \mathrm{~min}$. Tricholoroacetic acid $(2.5 \mathrm{ml})$ was added and the mixture was centrifuged at $650 \mathrm{~g}$ for $10 \mathrm{~min}$ The supernatant $(2.5 \mathrm{ml})$ was mixed with $2.5 \mathrm{ml}$ of distilled water and $0.5 \mathrm{ml}$ of ferric chloride $(10 \%)$ and the absorbance was measured at $700 \mathrm{~nm}$. The reducing power of the extracts was compared with that of L-ascorbic acid $(0.2 \mathrm{mg} / \mathrm{ml})$.

\subsubsection{DPPH Scavenging Activity}

All the herbal extracts along with BHA were evaluated for radical scavenging activity in the DPPH system [12, 13]. The extracts at a concentration of 50, 100 and 200 ppm $(1 \mathrm{ml})$ were taken in test tubes and $4 \mathrm{ml}$ of $0.1 \mathrm{mM}$ methanolic solution of DPPH were added to these tubes and shaken vigorously. The tubes were allowed to incubate in dark at $27^{\circ} \mathrm{C}$ for $20 \mathrm{~min}$. The control was prepared, as above without the extract and methanol was used for zero adjustment. Optical densities (OD) of the samples were measured at $517 \mathrm{~nm}$. Radical scavenging activity was expressed as the inhibition percentage and was calculated using the following formula:

Radical scavenging activity $(\%)=($ control OD - sample OD)/control OD $\times 100$.

\subsubsection{Total Flavonoids}

The amount of flavonoids was determined according to the colorimetric assay [14]. Aliquots of the aqueous solution of the extracts were mixed with $5 \%$ sodium nitrite solution $(0.3 \mathrm{ml})$ followed by $10 \%$ aluminium chloride solution $(0.3 \mathrm{ml})$. The solutions were incubated at ambient temperature for $5 \mathrm{~min}$, and then $2 \mathrm{ml}$ of $1 \mathrm{M}$ sodium hydroxide was added to the mixture. Volume of the mixture was made to $10 \mathrm{ml}$ with distilled water and the absorbance was determined at $510 \mathrm{~nm}$. A calibration curve was prepared with catechin and the results were expressed as mg catechin equivalents (CEQ)/100 $\mathrm{g}$ sample.

\subsubsection{Total Phenolics}

Total polyphenol content of herbal extracts was determined using Folin-Ciocalteu's reagent. The experimental samples in methanol were mixed with saturated sodium carbonate solution and Folin-Ciocalteu's reagent. The solutions were incubated in dark for $2 \mathrm{~h}$ and OD was measured at $765 \mathrm{~nm}$. Total polyphenol content of the herbal extracts was expressed as gallic acid equivalents per $100 \mathrm{~g}$ of sample [15].

\subsubsection{HPLC Analysis of Extracts}

Each extract $(100 \mathrm{mg})$ was dissolved in distilled water $(10 \mathrm{ml})$ and passed through a $0.45 \mu$ filter. $1 \mathrm{ml}$ of the filtrate was diluted to $10 \mathrm{ml}(1 \mathrm{mg} / \mathrm{ml})$ and $20 \mu l$ of this sample was injected. HPLC analysis was carried out using waters HPLC system consisting of waters binary HPLC 515 pump, manual injector 7725 and PDA detector. The column used was Wakosil $\mathrm{C}_{18}(250 \times 4.6 \mathrm{~mm}$ i. d. particle size $3 \mu \mathrm{m}$ ). The extracts were eluted with isocratic elution of mobile phase $(59.5 \%$ methanol, $39.5 \%$ water and $1 \%$ orthophosphoric acid) at $0.5 \mathrm{ml} / \mathrm{min}$ flow rate. The compounds were detected by waters PDA detector at a wavelength of $265 \mathrm{~nm}$.

\subsubsection{Determination of Synergistic Action}

Determination of synergistic effect on radical scavenging action of aqueous and alcoholic extracts of oregano, ajowan and country borage was carried out by DPPH method wherein the overall concentration of the extracts was maintained at 50, 100 and $200 \mathrm{ppm}$.

\subsubsection{Statistical Analysis}

All the analyses were carried out in triplicate and the results were shown as mean value with standard deviation. The obtained data were subjected to statistical analysis and means were compared by the Duncan's New multiple ranges test and presented.

\section{Results and Discussion}

\subsection{DPPH Scavenging Activity}

Determination of radical scavenging activity by DPPH is a rapid and reliable method to evaluate the antioxidant activity of the extracts. With this method, it is possible to determine the radical scavenging potential of the antioxidants by measuring the absorbance at $517 \mathrm{~nm}$. Antioxidants react with DPPH radical and convert it to 1 , 1-diphenyl-2-picrylhydrazine due to its hydrogen donating ability at a rapid rate. The degree of discoloration indicates the scavenging potential of the antioxidants. Among the herbs examined, oregano exhibited maximum scavenging activity $(88.2 \%, 82.3 \%)$ for both aqueous and alcoholic extracts (Table 1). This result was in good agreement with the literature reports on the antioxidant activity of the non-volatile constituents of oregano [16, 17]. Ajowan showed better radical scavenging activity $(86.9 \%, 68.4 \%)$ than Indian borage $(30.5 \%, 30.4 \%)$ at the concentration of $50 \mathrm{ppm}$ (Table 1). This result was in accordance with phenolic and the flavanoid content of the respective extracts (Table 2) as oregano extract possesses more phenolic components compared to ajowan and borage. Further, radical scavenging activity was sig- 
Table 1. Radical scavenging activity (RSA) of extracts of oregano, ajowan and Indian borage.

\begin{tabular}{ccccc}
\hline \multirow{2}{*}{ Herb } & \multirow{2}{*}{ Solvent } & \multicolumn{3}{c}{ Concentration of extracts and RSA (\%) } \\
\cline { 3 - 5 } & & $50 \mathrm{ppm}$ & $100 \mathrm{ppm}$ & $200 \mathrm{ppm}$ \\
\hline Oregano & Water & $88.17^{\mathrm{a}} \pm 0.21$ & $88.27^{\mathrm{a}} \pm 0.15$ & $88.57^{\mathrm{a}} \pm 0.31$ \\
& Alcohol & $82.27^{\mathrm{c}} \pm 0.25$ & $86.83^{\mathrm{c}} \pm 0.21$ & $88.10^{\mathrm{aa}} \pm 0.20$ \\
Ajowan & Water & $86.90^{\mathrm{b}} \pm 0.17$ & $87.37^{\mathrm{b}} \pm 0.15$ & $88.47^{\mathrm{a}} \pm 0.25$ \\
& Alcohol & $68.43^{\mathrm{d}} \pm 0.40$ & $80.43^{\mathrm{d}} \pm 0.15$ & $85.23^{\mathrm{b}} \pm 0.25$ \\
\multirow{2}{*}{ Borage } & Water & $30.50^{\mathrm{e}} \pm 0.40$ & $51.43^{\mathrm{e}} \pm 0.32$ & $71.27^{\mathrm{c}} \pm 0.31$ \\
& Alcohol & $30.43^{\mathrm{e}} \pm 0.35$ & $23.50^{\mathrm{f}} \pm 0.40$ & $54.40^{\mathrm{d}} \pm 0.44$ \\
\hline
\end{tabular}

Means of the same column followed by different letters in all tables differ significantly $(p \leq 0.05)$ according to Duncan's New Multiple Range test.

Table 2. Total phenolics and flavonoid content of extracts of oregano, ajowan and Indian borage.

\begin{tabular}{cccc}
\hline Herb & Solvent & $\begin{array}{c}\text { Total phenolic } \\
\text { content* }(\mathrm{g} \cdot \%)\end{array}$ & $\begin{array}{c}\text { Total flavonoid } \\
\text { content }(\mathrm{g} \cdot \%)\end{array}$ \\
\hline Oregano & Water & $27.7^{\mathrm{a}} \pm 0.04$ & $50.6^{\mathrm{a}} \pm 0.03$ \\
& Alcohol & $27.6^{\mathrm{a}} \pm 0.05$ & $50.4^{\mathrm{a}} \pm 0.03$ \\
Ajowan & Water & $6.7^{\mathrm{b}} \pm 0.01$ & $24.4^{\mathrm{b}} \pm 0.02$ \\
& Alcohol & $5.4^{\mathrm{c}} \pm 0.01$ & $11.8^{\mathrm{c}} \pm 0.04$ \\
Borage & Water & $4.2^{\mathrm{d}} \pm 0.03$ & $5.5^{\mathrm{d}} \pm 0.03$ \\
& Alcohol & $1.8^{\mathrm{e}} \pm 0.02$ & $1.1^{\mathrm{e}} \pm 0.04$ \\
\hline
\end{tabular}

*expressed as gallic acid equivalents per $100 \mathrm{~g}$ of sample.

nificantly higher when water was used as the extracting solvent compared to alcohol in all the herbs. This may due to higher polarity of water for extracting the bio-active constituents from the herbs.

\subsection{Effect of Concentration of Extracts on Antioxidant Activity}

The antioxidant activity was determined by using a $\beta$-carotene/linoleic acid system. In this model system, $\beta$-carotene undergoes a rapid discoloration in the absence of an antioxidant. The free linoleic acid radical formed upon the abstraction of a hydrogen atom from one of its methylene groups attacks the $\beta$-carotene molecule, which loses the double bonds and its characteristic orange colour.

Ethanolic and aqueous extracts from oregano, ajowan and Indian borage exhibited effective antioxidant activity at all concentrations studied. The results (Figures 1 and 2) indicated that antioxidant activity of extracts increased with increasing concentration. Yen and Lee [18] found that antioxidant activity of the extract from Aspergillus candidus broth filtrate increased with increasing concentration and reached maximum after $200 \mathrm{ppm}$. The extracts of oregano and ajowan exhibited stronger antioxidant activity than that of Indian borage apparently due to difference in constituent antioxidant compounds in the extracts.

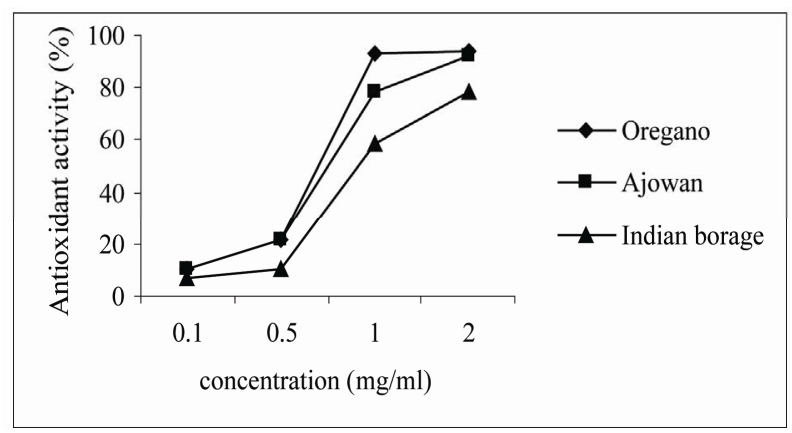

Figure 1. Antioxidant activity of aqueous extracts of herbs.

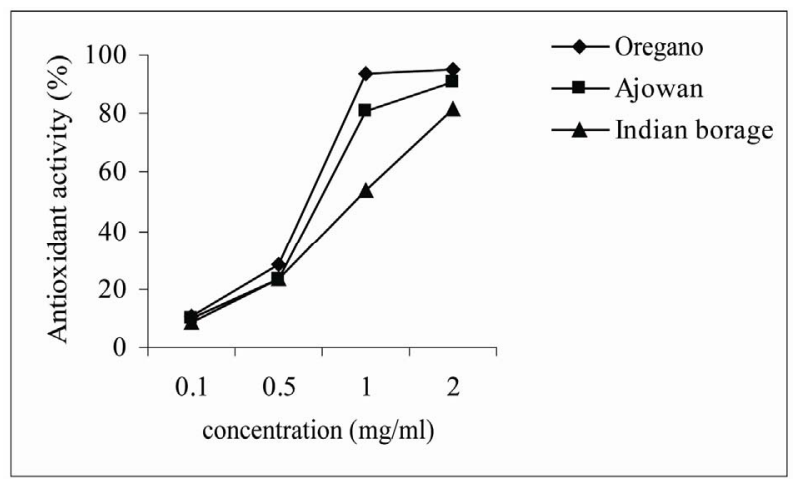

Figure 2. Antioxidant activity of alcoholic extracts of herbs.

\subsection{Reducing Power}

During the reducing power assay, the presence of reducing agents in the test samples would result in reducing $\mathrm{Fe}^{3+}$ ferricyanide complex to the ferrous form $\left(\mathrm{Fe}^{2+}\right)$. By measuring the Prussian blue absorption at $700 \mathrm{~nm}$, formation of $\mathrm{Fe}^{2+}$ can be monitored [19]. The reducing power of ethanolic and aqueous extracts increased with increase in concentration. The reducing power of ethanolic extracts at $0.5,1,1.5$ and $2 \mathrm{mg} / \mathrm{ml}$ was $0.8,1.0,1.6$ and 1.8 for oregano, $0.26,0.28,0.40$ and 0.45 for ajowan, $0.11,0.12,0.14$ and 0.15 for Indian borage respectively. The reducing power of aqueous extracts at $0.5,1,1.5$ and $2 \mathrm{mg} / \mathrm{ml}$ was $0.8,1.1,1.3$ and $1.8 \mathrm{mg} / \mathrm{ml}$ for oregano, $0.29,0.3,0.35$ and $0.45 \mathrm{mg} / \mathrm{ml}$ for ajowan, 0.11, 0.14, 0.18 and $0.19 \mathrm{mg} / \mathrm{ml}$ for Indian borage. At the same concentration levels, oregano extracts showed higher reducing power than ajowan and Indian borage extracts. In comparison, the reducing power of L-ascorbic acid at a concentration level of $0.2 \mathrm{mg} / \mathrm{ml}$ was of 0.82 .

\subsection{Total Phenolics and Flavonoids}

The total phenolic content of ethanolic and aqueous extracts from oregano, ajowan and Indian borage extracts was estimated, since phenolics could contribute to its overall antioxidant activity. Phenolics were detected in all samples (Table 2). The ethanolic and aqueous ex- 
tracts of oregano had the highest total phenolic content (TPC) of $27.6 \mathrm{~g} . \%$ and $27.7 \mathrm{~g} . \%$ respectively followed by ajowan and Indian borage. The lowest TPC value of 1.8 $\mathrm{g} . \%$ was detected in the ethanolic extract of Indian borage. In addition, the aqueous extracts of ajowan and borage had higher TPC value than the ethanolic extracts. These results suggested the potential influence of extracting solvent on total phenolic content.

Total flavonoid content (TFC) of ethanolic and aqueous extracts from oregano, ajowan and Indian borage was measured using aluminium chloride colorimetric method (Table 2). The results showed that the TFC of extracts of oregano had the highest TFC content of $50.6 \mathrm{~g} \cdot \%$ (catechin equivalents) followed by ajowan and Indian borage extracts as shown in Table 2. Even though it is apparent that the flavonoids are the important phenolic compounds contributing to the AA of extracts, it is possible that other phenolic compounds could also contribute to the antioxidant properties of these extracts.

\subsection{HPLC Analysis of Extracts}

The HPLC profiles of ethanolic and aqueous extracts (Figure 3) of oregano, ajowan and Indian borage did exhibit distinct differences in their constituents. Also, the components in these extracts were different from the major phenolic constituents, thymol and carvacrol, of these herbs. Further isolation and characterization of these anti-oxidant components would be necessary to understand their contribution to the bio-active properties of these extracts.

\subsection{Synergistic Action of Extracts}

Results of study of synergistic effect of the combined extracts are furnished in Table 3. Addition of oregano extract appreciably enhanced the RSA of ajowan and borage extracts even at $50 \mathrm{ppm}$ concentration. These results shows that oregano extracts when used in combination with ajowan and Indian borage improved the radical scavenging effect of the latter two herbs. This was the first report of comparison and synergistic effect of these herbs and the finding could have very important applications in design of functional foods.

In summary, this study indicated that oregano, ajowan and Indian borage are potential dietary sources of natural antioxidants. Aqueous extract of oregano showed higher reducing power, total phenolic content and total flavonoids than that of ajowan and Indian borage. Aqueous and ethanolic extracts of oregano exhibited higher radical

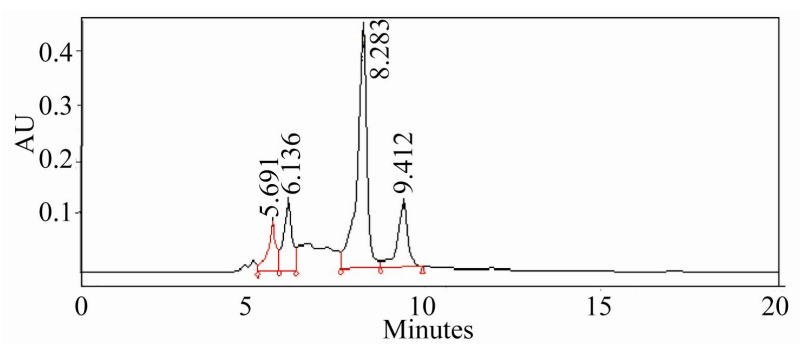

(a)

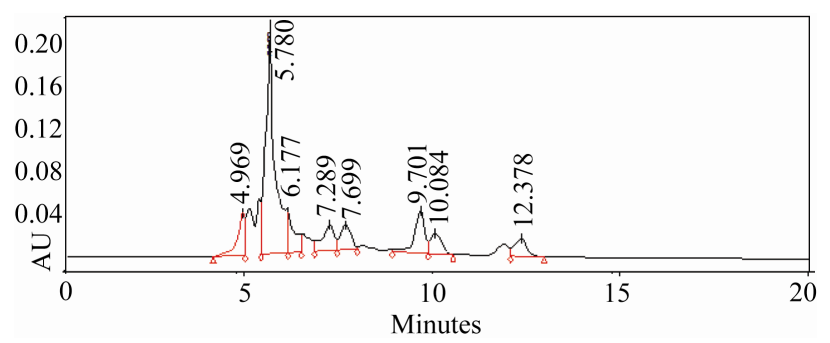

(b)

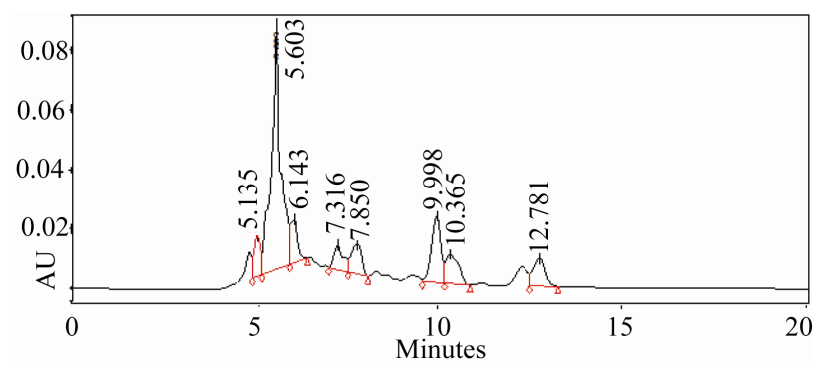

(c)

Figure 3. HPLC profiles of alcoholic extracts of (a): Oregano, (b): Ajowan and (c): Borage.

Table 3. Synergistic radical scavenging action of extracts of oregano, ajowan and Indian borage.

\begin{tabular}{|c|c|c|c|c|}
\hline \multirow{2}{*}{ Herb } & \multirow{2}{*}{ Solvent } & \multicolumn{3}{|c|}{ Concentration of extracts and RSA (\%) } \\
\hline & & $50 \mathrm{ppm}$ & $100 \mathrm{ppm}$ & $200 \mathrm{ppm}$ \\
\hline \multirow{2}{*}{ Oregano + Ajowan } & Water & $91.5^{\mathrm{a}} \pm 0.1$ & $90.5^{b} \pm 0.2$ & $90.7^{\mathrm{e}} \pm 0.1$ \\
\hline & Alcohol & $92.3^{\mathrm{a}} \pm 0.1$ & $91.3^{\mathrm{a}} \pm 0.2$ & $92.0^{c} \pm 0.2$ \\
\hline \multirow{2}{*}{ Ajowan + Borage } & Water & $31.8^{\mathrm{d}} \pm 0.3$ & $57.8^{\mathrm{d}} \pm 0.1$ & $90.4^{\mathrm{e}} \pm 0.1$ \\
\hline & Alcohol & $41.4^{\mathrm{c}} \pm 0.2$ & $87.9^{\mathrm{c}} \pm 0.2$ & $93.1^{\mathrm{b}} \pm 0.2$ \\
\hline \multirow{2}{*}{ Borage + Oregano } & Water & $90.9^{b} \pm 0.2$ & $91.5^{\mathrm{a}} \pm 0.2$ & $91.8^{\mathrm{d}} \pm 0.2$ \\
\hline & Alcohol & $92.7^{\mathrm{a}} \pm 0.2$ & $91.9^{\mathrm{a}} \pm 0.2$ & $92.5^{\mathrm{c}} \pm 0.1$ \\
\hline \multirow{2}{*}{ Oregano + Ajowan + Borage } & Water & $90.4^{b} \pm 0.1$ & $91.2^{\mathrm{a}} \pm 0.2$ & $95.5^{\mathrm{a}} \pm 0.2$ \\
\hline & Alcohol & $92.5^{\mathrm{a}} \pm 0.2$ & $92.0^{\mathrm{a}} \pm 0.2$ & $92.5^{\mathrm{c}} \pm 0.1$ \\
\hline
\end{tabular}


scavenging activity (RSA) than those of ajowan and Indian borage extracts. Antioxidant activity of oregano, ajowan and Indian borage extracts increased with increasing concentrations, ranging from 0.1 to $1 \mathrm{mg} / \mathrm{ml}$ and then reached a plateau at concentrations ranging from 1 to $2 \mathrm{mg} / \mathrm{ml}$. Higher antioxidant properties of oregano and ajowan Indian borage extracts can be attributed to differences in constitution of the antioxidant components. Synergistic studies showed that the addition of oregano extract appreciably enhanced the RSA of ajowan and borage extracts even at $50 \mathrm{ppm}$ concentration. These ethanolic and aqueous extracts have the potential to be used as natural food antioxidants in place of synthetic additives.

\section{Acknowledgements}

Authors thank Dr. V. Prakash, Director, CFTRI, Mysore, India, for his constant support and encouragement to carry out this work.

\section{REFERENCES}

[1] Y. S. Velioglu, G. Mazza, L. Gao and B. D. Oomach, "Antioxidant Activity and Total Phenolics in Selected Fruits, Vegetables and Grain Products," Journal of Agricultural and Food Chemistry, Vol. 46, No. 10, 1998, pp. 4113-4117. doi:10.1021/jf9801973

[2] H. L. Madson and G. Bertelsen, "Spices as Antioxidants," Trends in Food Science and Technology, Vol. 6, No. 8, 1995, pp. 271-277. doi:10.1016/S0924-2244(00)89112-8

[3] C. A. Rice-Evans and N. J. Miller, "Antioxidant Activities of Flavonoids as Bioactive Components of Foods," Biochemical Society Transactions, Vol. 24, No. 3, 1996, pp. 790-795. doi:10.1042/bst0240790

[4] K. Hirasa and M. Takemasa, "Spice Science and Technology,” Marcel Dekker, New York, 1998.

[5] K. Srinivasan, "Role of Spices beyond Food Flavoring: Nutraceuticals with Multiple Health Effects," Food Reviews International, Vol. 21, No. 2, 2005. pp. 167-188. doi:10.1081/FRI-200051872

[6] N. Nakatani, "Phenolic Antioxidants from Herbs and Spices," Biofactors, Vol. 13, No. 1-4, 2000, pp. 141-146. doi:10.1002/biof.5520130123

[7] A. B. Caragay, "Cancer-Preventive Foods and Ingredients," Food Technology, Vol. 46, No. 4, 1992, pp. 65-68.

[8] P. S. Murthy, B. B. Borse, H. Khanum and P. Srinivas, "Ochratoxin Inhibition by Ajowan (Trachysper mumammi) Ethanolic Extract," Turkish Journal of Biology, Vol. 33, No. 3, 2009, pp. 211-217.

[9] P. S. Murthy, K. Ramalakshmi and P. Srinivas, "Fungi- toxic Activity of Indian Borage (Plectranthus amoboinicus) Volatiles," Food Chemistry, Vol. 114, No. 3, 2009, pp.1014-1018. doi:10.1016/j.foodchem.2008.10.064

[10] M. S. Taga, E. E. Miller and D. E. Pratt, "China Seeds as Source of Natural Lipid Antioxidant," Journal of the American Oil Chemists Society, Vol. 61, No. 5, 1984, pp. 928-931.

[11] M. Oyaizu, "Studies on Products of Browning Reaction-Antioxidant Activities of Products of Browning Reaction Prepared from Glucoamine," Japanese Journal of Nutrition, Vol. 44, 1986, pp. 307-315.

[12] M. S. Blois, "Antioxidant Determination by the Use of Stable Free Radical," Nature, Vol. 181, 1958, pp. 11991200. doi:10.1038/1811199a0

[13] M. Oktay, I. Culcin and O. I. Kufrevioglu, "Determination of in Vitro Antioxidant Activity of Fennel (Foeniculum vulgare) Seed Extracts," Lebensmittel-Wissenschaft und-Technologie, Vol. 36, No. 2, 2003, pp. 263-271.

[14] D. O. Kim, S. W. Jeong, and C. Y. Lee, "Antioxidant Capacity of Phenolic Phytochemicals from Various Cultivars of Plums," Food Chemistry, Vol. 81, No. 3, 2003, pp. 321-326. doi:10.1016/S0308-8146(02)00423-5

[15] T. Swain and W. E. Hillis, "The Phenolic Constituents of Prunus domestica. I. the Quantitative Analysis of Phenolic Constituents," Journal of the Science of Food and Ariculture, Vol. 10, No. 1, 1959, pp. 63-68. doi:10.1002/jsfa. 2740100110

[16] T. Kulisic, A. Krisko, V. Dragovic-Uzelac, M. Milos and G. Pifat, "The Effects of Essential Oils and Aqueous Tea Infusions of Oregano (Origanum vulgare L. spp. Hirtum), Thyme (Thymus vulgaris L.) and Wild Thyme (Thymus serpyllum L.) on the Copper-Induced Oxidation of Human Low-Density Lipoproteins," International Journal of Food Sciences and Nutrition, Vol. 58, No. 2, 2007, pp. 87-93 doi:10.1080/09637480601108307

[17] L. Vasiliki and B. Dimitrios, "Nutrient Antioxidants in Oregano," International Journal of Food Sciences and Nutrition, Vol. 47, No. 6, 1996, pp. 493-497. doi:10.3109/09637489609031878

[18] G. C. Yen and C. E. Lee, "Antioxidative Properties of Extracts from Aspergillus candidus Broth Filtrate," Journal of the Science of Food and Agriculture, Vol. 75, No. 3, 1997, pp. 326-332. doi:10.1002/(SICI)1097-0010(199711)75:3<326::AID-JS FA882>3.0.CO;2-U

[19] Y. C. Chung, C. T. Chang, W. W. Chao, C. F. Lin and S. T. Chou, "Antioxidative Activity and Safety of the 50\% Ethanolic Extract from Red Bean Fermented by Bacillus Subtilis IMR-NK1," Journal of Agricultural and Food Chemistry, Vol. 50, No. 8, 2002, pp. 2454-2458. doi:10.1021/jf011369q 